\title{
BMJ
}

\section{Familial risk of oral clefts by morphological type and severity: population based cohort study of first degree relatives}

\author{
Åse Sivertsen, consultant plastic surgeon, ${ }^{1,2}$ Allen J Wilcox, senior investigator, ${ }^{3}$ Rolv Skjærven, professor, ${ }^{2}$ \\ Hallvard Andreas Vindenes, consultant plastic surgeon, ${ }^{1}$ Frank Åbyholm, professor, ${ }^{4}$ Emily Harville, \\ assistant professor, ${ }^{5}$ Rolv Terje Lie, professor $^{2}$
}

${ }^{1}$ Department of Plastic Surgery, Haukeland University Hospital, No-5021 Bergen, Norway

${ }^{2}$ Department of Public Health and Primary Health Care, University of Bergen, Kalfarveien 1, N-5018 Bergen

${ }^{3}$ Epidemiology branch, National Institute of Environmental Health Sciences, NIH, Durham, NC 27709, USA

${ }^{4}$ Department of Plastic Surgery, Rikshospitalet, N-0027 Oslo, Norway

${ }^{5}$ Department of Epidemiology, Tulane University School of Public Health and Tropical Medicine, New Orleans, LA 70112, USA

Correspondence to: Å Sivertsen ase.sivertsen@isf.uib.no

doi:10.1136/bmj.39458.563611.AE

\section{ABSTRACT}

Objective To estimate the relative risk of recurrence of oral cleft in first degree relatives in relation to cleft morphology.

Design Population based cohort study.

Setting Data from the medical birth registry of Norway linked with clinical data on virtually all cleft patients treated in Norway over a 35 year period.

Participants 2.1 million children born in Norway between 1967 and 2001, 4138 of whom were treated for an oral cleft.

Main outcome measure Relative risk of recurrence of isolated clefts from parent to child and between full siblings, for anatomic subgroups of clefts.

Results Among first degree relatives, the relative risk of recurrence of cleft was 32 (95\% confidence interval 24.6 to 40.3) for any cleft lip and 56 (37.2 to 84.8) for cleft palate only ( $P$ difference $=0.02$ ). The risk of clefts among children of affected mothers and affected fathers was similar. Risks of recurrence were also similar for parentoffspring and sibling-sibling pairs. The "crossover" risk between any cleft lip and cleft palate only was 3.0 (1.3 to 6.7). The severity of the primary case was unrelated to the risk of recurrence.

Conclusions The stronger family recurrence of cleft palate only suggests a larger genetic component for cleft palate only than for any cleft lip. The weaker risk of crossover between the two types of cleft indicates relatively distinct causes. The similarity of mother-offspring, fatheroffspring, and sibling-sibling risks is consistent with genetic risk that works chiefly through fetal genes. Anatomical severity does not affect the recurrence risk in first degree relatives, which argues against a multifactorial threshold model of causation.

\section{INTRODUCTION}

Oral clefts are one of the most common birth defects in humans. ${ }^{1}$ The birth prevalence in Norway is 2.2 per 1000 live births, ${ }^{2}$ among the highest rates of clefts in the Western world. The defects range from mild forms to complete clefts affecting both the lip and the palate. Although Online Mendelian Inheritance in Man
(www.ncbi.nlm.nih.gov/Omim/) lists more than 400 mendelian disorders associated with oral clefts, most oral clefts appear as isolated defects without signs of malformation syndromes. The genetic and environmental causes of non-syndromic oral clefts are largely unknown.

Given the uncertainty about the causes of clefts, the tendency for clefts to recur in families is striking. Estimates of the risk of recurrence for first degree relatives (defined as the prevalence of clefting in first degree relatives compared with the population prevalence) range from 24 -fold to 82 -fold. ${ }^{34}$ Such estimates are useful for genetic counselling. ${ }^{56}$ They can also provide evidence for inferences on causation. Fogh-Andersen showed that cleft palate is causally different from cleft lip with and without cleft palate by showing that families at high risk for one are not at increased risk for the other. ${ }^{7}$

We used a population based study of clinically verified cases to estimate familial risks of recurrence of clefting in first degree relatives and to describe the risk of recurrence by severity of the cleft. We also considered whether having a cleft of a certain type (or having a child with a cleft) affects subsequent reproduction.

\section{METHODS}

The population based medical birth registry of Norway includes all children born in Norway since 1967 (about 2.1 million). All live births and stillbirths at a gestational age of at least 16 weeks are included in the registry. Babies born with oral clefts in Norway are treated in one of two national centres-Haukeland University Hospital and Rikshospitalet University Hospital. From 1967 to 2001,4138 patients with oral clefts were treated in these hospitals. Two experienced clinicians classified the clefts morphologically for consistent application of the definitions of severity. We linked these clinical data to the population registry by using Norway's unique national person identification numbers. Data were anonymised after linkage. This allowed us to combine high quality clinical information on cleft 


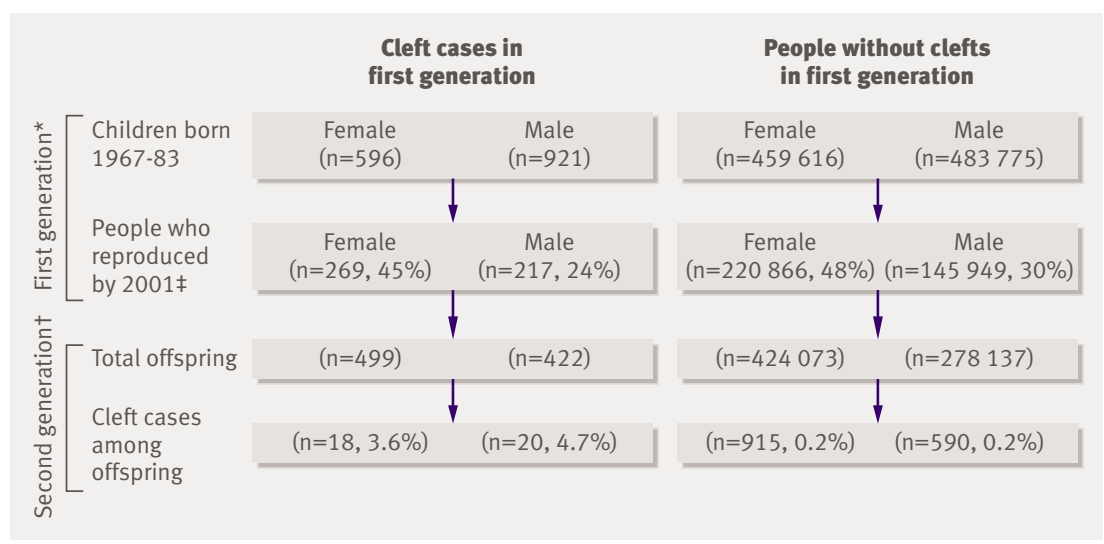

Fig 1 | Follow-up through generations. *People without non-cleft birth defects; diagnosis of cleft was clinically verified. $\nmid$ Diagnosis of cleft was verified in medical birth registry, in clinical data, or in both; stillborn babies and people with non-cleft birth defects are included. $\ddagger$ Overall marked lower proportion of men who have reproduced is because women tend to have children with men older than themselves (men born before 1967 and not included in study cohort)

morphology with virtually complete ascertainment of biological family members for the whole country over a 35 year period.

Between 1967 and 1983, 944908 babies were born in Norway. We excluded plural births from these analyses, as twinning has a heritable component and is also associated with a risk of oral clefts. ${ }^{8}$ We were able to follow this cohort of children to 2001, at which time the cohort was 18-34 years of age. During this time, 367301 of the babies reported in the registry had become parents of babies also reported in the registry (fig 1 ).

We expressed the risk of recurrence of clefts from parent to child as relative risk with $95 \%$ confidence intervals. We estimated relative risks by odds ratios in logistic regression models in Stata 9.2. We used robust estimation of variances to account for correlation between repeated observations within nuclear families. When we compared the risks of two different outcomes, such as the risk of cleft palate only after cleft lip with that of cleft lip after cleft palate only, we split the reference group randomly into two halves that were used as reference for each of the two risks.

We also linked full siblings in order to estimate the recurrence risk of clefts in sibships. By 2001, 572772 babies had at least one subsequent full sibling in the registry (with the same mother and father) (fig 2). Again, we estimated the risk of recurrence as the relative risk of recurrence.

We estimated the risk of recurrence of the same or dissimilar cleft types among these first degree relatives (offspring or siblings) by using three categories of clefts: cleft lip only, cleft lip and palate, and cleft palate only. Cleft lip only includes cases of cleft lip confined to the primary palate, cleft lip and palate includes cases in which the cleft extends through the primary palate into the secondary palate, and cleft palate only includes cases with clefting in the secondary palate only. We also combined cleft lip only and cleft lip and palate into the more general category of "cleft lip."
We graded the severity of the cleft on the basis of the morphological details of the cleft in the clinical records (initial surgical report, photographs, and study casts). ${ }^{2}$ We classified cleft lip by laterality (right or left) and graded it as "1" (mild) when restricted to the lip, "2" (moderate) with cleft in the lip and alveolar ridge, and " 3 " (severe) with complete cleft of the primary palate. We graded cleft palate as "1" (mild) in cases with submucous cleft of the soft palate, " 2 " (moderate) with overt cleft of the soft palate, and " 3 " (severe) with cleft of the soft and hard secondary palate.

We excluded cleft index cases with any other birth defect ( $10 \%$ of cleft lip, $29 \%$ of cleft palate only) because of the possibility that syndromic cases might have a different underlying genetic predisposition, with a correspondingly different risk of recurrence. We also restricted the index cleft cases to those who had been referred for surgical treatment, as these cases had a morphological description of their cleft. When estimating recurrence risks, we considered the total risk of oral clefts, including stillbirths, cases with other birth defects, and cases in the registry who never received surgery (usually because of death). In the estimations of severity, side, and location of the cleft in the recurrent cases, we could use only the clinically verified cases, as these had a morphological description of their clefts. If the description of the cleft in the clinical record did not match the diagnosis in the medical birth registry, we used the diagnosis in the clinical record.

\section{RESULTS}

\section{Follow-up from parent to child}

We followed children born between 1967 and 1983, allowing follow-up to at least age 18 by 2001. Of the female babies born with a cleft, $45 \%$ had become mothers by 2001 compared with $48 \%$ of those without a recorded birth defect $(\mathrm{P}=0.16)$ (fig 1). Among male babies, $24 \%$ of those with a cleft and $30 \%$ of those without birth defects had become fathers by 2001 $(\mathrm{P}<0.001)$. Among those who had become parents, the total number of children was the same (mean 1.9)

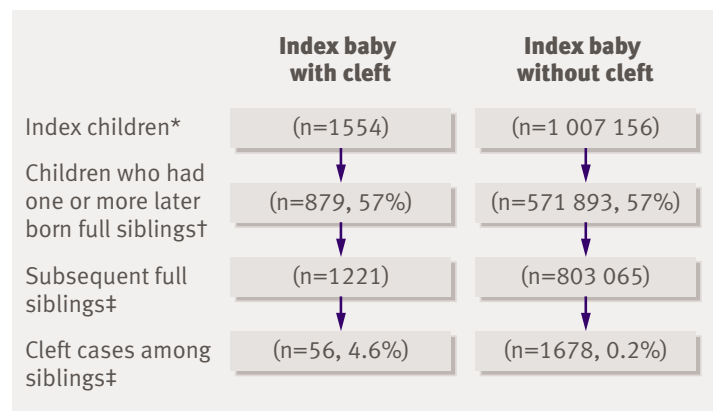

Fig 2 Follow-up of babies who had at least one subsequent full sibling. *A woman's first recorded baby; stillborn babies and babies with non-cleft birth defects are not included; diagnosis of cleft was verified in clinical data. †Number of mothers who had more than one baby (not plural births) with the same partner. $\ddagger$ Stillborn babies and babies with non-cleft births defects are included; diagnosis of cleft was verified in medical birth registry, in clinical data, or in both 
Table 1 | Relative risk* ${ }^{\star}$ f recurrence across generations of cleft lip only (CLO), cleft lip and palate (CLP), and cleft palate only (CPO)

\begin{tabular}{|c|c|c|c|c|c|c|c|}
\hline \multirow{2}{*}{$\frac{\text { Index cases } \dagger \text { (parent) }}{\text { Main categories of cleft }}$} & \multicolumn{4}{|c|}{ Recurrent cases $\dagger$ (offspring) } & \multicolumn{3}{|c|}{ Relative risk* $(95 \%$ confidence interval) } \\
\hline & At risk & CLO & CLP & CPO & CLO & CLP & CPO \\
\hline Cleft lip only $(n=154)$ & 293 & 3 & 7 & 2 & $19(6.1$ to 57.5$)$ & $29(13.6$ to 59.8$)$ & $9(2.3$ to 37.4$)$ \\
\hline Cleft lip and palate $(n=182)$ & 340 & 5 & 8 & 1 & $27(11.2$ to 64.9$)$ & $28(14.0$ to 56.7$)$ & $4(0.6$ to 28.5$)$ \\
\hline Cleft palate only $(n=150)$ & 288 & 0 & 1 & 11 & - & $4(0.6$ to 29.1$)$ & $\begin{array}{c}54(29.7 \text { to } \\
98.0)\end{array}$ \\
\hline No clefts (reference) $(n=366815)$ & 702210 & 388 & 601 & 516 & 1.0 & 1.0 & 1.0 \\
\hline
\end{tabular}

*Relative risks (estimated as odds ratios in logistic regression models) are ratios of risk of recurrence and risk in reference group.

†Index cases are clinically verified cleft cases without non-cleft birth defects. Recurrent cases include all recorded cases among stillborn or live born babies, cases with or without other defects, and cases that were registered either in clinical data or in medical birth registry.

whether or not the parent had oral clefts. Overall, the prevalence of clefts in offspring was 3.6\% for mothers with oral clefts and $4.7 \%$ for fathers with oral clefts $(\mathrm{P}$ difference $=0.39$ ), whereas the prevalence for parents without clefts was $0.2 \%$.

\section{Follow-up in siblings}

We found 1554 women whose first registered child had an oral cleft (fig 2). Of these women, 879 (57\%) had a subsequent child with the same father, the same proportion as for mothers whose first registered child had no defect. Among the subsequent siblings of the cleft cases, $4.6 \%$ had an oral cleft compared with $0.2 \%$ of the siblings of unaffected babies.

\section{Specificity in recurrence of cleft types}

The estimates of recurrence did not differ for parentoffspring recurrence and sibling-sibling recurrence for any of the cleft types (cleft lip only, $\mathrm{P}$ difference $=0.32$; cleft lip and palate, $\mathrm{P}$ difference $=0.21$; cleft palate only, $\mathrm{P}$ difference $=0.86$ ) (tables 1 and 2 ). We therefore pooled the generational data with the full sibling data to estimate joint recurrence risks of subgroups of clefts for first degree relatives.

When we compared the relative risk of recurrence of cleft lip only (relative risk $=30.0$, 95\% confidence interval 16.6 to 54.2 ) with that of cleft lip and palate (41.1, 27.8 to 60.7), we found no statistical evidence of difference $(\mathrm{P}=0.38)$. The risk of cleft lip only was similar after cleft lip only and after cleft lip and palate $(\mathrm{P}$ difference $=0.50$ ), and the risk of cleft lip and palate was similar after cleft lip only and after cleft lip and palate $(\mathrm{P}$ difference $=0.36)$. These numbers support the assumption that cleft lip only and cleft lip and palate are different expressions of the same underlying condition. We therefore pooled these two types into a general category of cleft lip, containing all isolated cleft lip cases with or without cleft palate.

\section{Recurrence for first degree relatives combined}

We estimated the overall risk of recurrence of cleft lip as 32 -fold (95\% confidence interval 24.6 to 40.3 ) (table 3). We found no difference in recurrence of cleft lip from mother to offspring or from father to offspring (relative risks 27.1 and 26.6; $\mathrm{P}$ difference $=0.97$ ). Recurrence of cleft lip in siblings was slightly higher than recurrence from parents to offspring (relative risks 35.1 and 26.7), but these estimates were also not significantly different (P difference $=0.31$ ).

The overall recurrence risk of cleft palate only was 56-fold (37.2 to 84.8) (table 4) and significantly different from recurrence of cleft lip ( $\mathrm{P}$ difference $=0.02$ ). Although cleft lip and cleft palate only have long been considered to be distinct defects, we found a threefold elevated risk of the other after the occurrence of either one (95\% confidence interval 1.3 to $6.7 ; \mathrm{P}=0.007)$. We found no apparent differences between mother-offspring and father-offspring recurrence or between parent-offspring and sibling-sibling recurrence for cleft palate only (table 4 ).

\section{Recurrence by severity}

We found little evidence that the risk of recurrence was related to the severity of the defect. Relative risk of recurrence of cleft lip was 26 after a mild cleft lip (severity 1), 43 after a moderate cleft lip (severity 2), and 31 after a severe cleft lip (severity 3$)(P$ difference $=0.53)$ (table 5). The mean severity of cleft lip in the recurrent

Table 2| Relative risk ${ }^{\star}$ of recurrence between subsequent full siblings of cleft lip only (CLO), cleft lip and palate (CLP), and cleft palate only (CPO)

\begin{tabular}{|c|c|c|c|c|c|c|c|}
\hline \multirow{2}{*}{$\begin{array}{l}\text { Index cases } † \text { (first child) } \\
\text { Main categories of cleft }\end{array}$} & \multicolumn{4}{|c|}{ Recurrent cases $†$ (full siblings) } & \multicolumn{3}{|c|}{ Relative risk* (95\% confidence interval) } \\
\hline & At risk & CLO & CLP & CPO & CLO & CLP & CPO \\
\hline Cleft lip only $(n=274)$ & 388 & 8 & 9 & 0 & $37(18.3$ to 74.7$)$ & 30 (15.5 to 58.8$)$ & - \\
\hline Cleft lip and palate $(n=352)$ & 491 & 5 & 18 & 2 & 18 (7.4 to 43.9$)$ & $48(30.2$ to 77.4$)$ & $6(1.4$ to 22.3$)$ \\
\hline Cleft palate only $(n=253)$ & 342 & 0 & 0 & 14 & - & - & $58(32.8$ to 102.8$)$ \\
\hline No clefts (reference) $(n=571$ 893) & 803065 & 457 & 631 & 590 & 1.0 & 1.0 & 1.0 \\
\hline
\end{tabular}

*Relative risks (estimated as odds ratios in logistic regression models) are ratios of risk of recurrence and risk in reference group. †Index cases are clinically verified cleft cases without non-cleft birth defects. Recurrent cases include all recorded cases among stillborn or live born babies, cases with or without other defects, and cases that were registered either in clinical data or in medical birth registry. 
Table $3 \mid$ Relative risk* of recurrence for cleft lip (with or without cleft palate) for first degree relatives of an index case with isolated cleft lip $\dagger$

\begin{tabular}{lccc} 
& & Recurrence of cleft lip (with or without cleft palate) \\
\cline { 2 - 4 } Familial relationship & At risk & $\begin{array}{c}\text { Recurrences of cleft } \\
\text { lip }\end{array}$ & $\begin{array}{c}\text { Relative risk* (95\% } \\
\text { confidence interval) }\end{array}$ \\
Mother-offspring & 295 & 11 & $27(14.9$ to 49.2) \\
\hline Father-offspring & 338 & 12 & $27(15.0$ to 47.2$)$ \\
\hline Parent-offspring total & 633 & 23 & $27(17.7$ to 40.3) \\
\hline Subsequent full sibling & 879 & 40 & $35(25.5$ to 48.4) \\
\hline All first degree relatives & 1512 & 63 & $32(24.6$ to 40.3)
\end{tabular}

* Relative risks (estimated as odds ratios in logistic regression models) are ratios of risk of recurrence and risk in reference group without index cleft cases.

†ndex cases are clinically verified cleft cases without non-cleft birth defects. Recurrent cases include all recorded cases among stillborn or live born babies, cases with or without other defects, and cases that were registered either in clinical data or in medical birth registry.

case (on the scale of 1-3) was 2.4 after a mild cleft lip, 2.3 after a moderate cleft lip, and 2.3 after a severe cleft lip. Relative risk of recurrence was 30 with unilateral cleft lip in the index case and 39 with bilateral cleft lip (P difference $=0.35$ ).

We did the same analysis for cleft palate. Relative risk of recurrence was 44 after mild (submucous) cleft palate only, 41 after moderate (soft palate) cleft palate only, and 82 after severe (hard palate) cleft palate only ( $\mathrm{P}$ difference $=0.34)$. The mean severity of cleft palate was 1.5 after mild cleft palate only, 2.1 after moderate cleft palate only, and 2.5 after severe cleft palate only (not significantly different, $\mathrm{P}=0.20$ ).

The risk of recurrence of cleft lip in first degree relatives was not different with right sided or left sided unilateral cleft lip (data not shown) (P difference $=0.59$ ). We found no apparent tendency for cleft lip to re-occur on the same side as the index case. We found the well known left predominance of cleft lip in cases born into unaffected families as well as in the recurrent cases.

\section{DISCUSSION}

We found almost complete specificity of risk of recurrence for the two major types of clefts-any cleft lip and cleft palate only-showing their nearly distinct causes. Within cleft lip cases, we found no evidence for specificity of risk between cleft lip only and cleft lip and palate; risks for both were high after either. This supports the assumption that these two types of cleft lip comprise a single genetic risk group.

The apparent absence of an effect of severity of cleft on risk of recurrence has implications for genetic counselling. Severe clefting in one child does not increase the risk of a subsequent child being affected; similarly, the occurrence of a mild defect does not insulate the family from the generally high recurrence of clefts or from a severe version of the defect should it occur in other family members.

\section{Strengths and weaknesses}

Data quality —This study combined a large sample size and population coverage with a high level of clinical detail and verification from surgical examinations. ${ }^{2}$ The use of the compulsory national registration of births in the medical birth registry, together with low rates of emigration, has made the data virtually complete.

Study design -We calculated risks of recurrence on the basis of treated cases of index oral clefts cases with siblings or offspring with oral clefts who did not necessarily have to be live born and survive. The risks might be different for those whose index case was stillborn or did not survive to surgery. Given the low absolute risk of clefts even among first degree relatives of clefts cases (less than 5\%), odds ratios provide a good estimate of the relative risk. We confirmed this by using

Table 4 | Relative risk of recurrence for cleft palate only (without cleft lip) for first degree relatives of an index case with isolated cleft palate only $\dagger$

\begin{tabular}{|c|c|c|c|c|}
\hline \multirow[b]{2}{*}{ Familial relationship } & \multicolumn{4}{|c|}{ Recurrence of cleft palate only } \\
\hline & At risk & $\begin{array}{l}\text { Recurrences of cleft } \\
\text { palate only }\end{array}$ & $\begin{array}{l}\text { Relative risk* }(95 \% \\
\text { confidence interval) }\end{array}$ & P difference \\
\hline Mother-offspring & 204 & 7 & $48(22.7$ to 103.1$)$ & \multirow{2}{*}{0.60} \\
\hline Father-offspring & 84 & 4 & $68(25.3$ to 181.7$)$ & \\
\hline Parent-offspring total & 288 & 11 & $54(29.7$ to 98.0$)$ & \multirow{2}{*}{0.98} \\
\hline Subsequent full sibling & 342 & 14 & $58(32.8$ to 102.8$)$ & \\
\hline All first degree relatives & 630 & 25 & $56(37.2$ to 84.8$)$ & \\
\hline
\end{tabular}

* Relative risks (estimated as odds ratios in logistic regression models) are ratios of risk of recurrence and risk in reference group without index cleft cases.

†Index cases are clinically verified cleft cases without non-cleft birth defects. Recurrent cases include all recorded cases among stillborn or live born babies, cases with or without other defects, and cases that were registered either in clinical data or in medical birth registry. 
Table 5 Relative risk ${ }^{\star}$ of recurrence and mean severity of cleft in the recurrent cases $\uparrow$ for first degree relatives by severity of cleft lip (with or without cleft palate) and severity of cleft palate only in the index cases $\dagger$

\begin{tabular}{lcccc} 
& \multicolumn{4}{c}{ Recurrence of similar cleft type } \\
\cline { 2 - 5 } $\begin{array}{l}\text { Index cases: cleft type and } \\
\text { severity }\end{array}$ & At risk & $\begin{array}{c}\text { No of recurrent } \\
\text { cases }\end{array}$ & $\begin{array}{c}\text { Mean severity } \\
\text { of cleft } \neq\end{array}$ & $\begin{array}{l}\text { Relative risk* }(95 \% \\
\text { confidence interval) }\end{array}$ \\
\hline Mild & 438 & 15 & 2.4 & $26(15.4$ to 42.8) \\
\hline Moderate & 251 & 14 & 2.3 & $43(25.2$ to 72.6) \\
\hline Severe & 823 & 34 & 2.3 & $31(22.3$ to 43.7) \\
\hline Cleft palate only & 96 & 3 & 1.5 & $44(13.8$ to 139.2) \\
\hline Mild & 299 & 9 & 2.1 & 41 (19.9 to 85.9) \\
\hline Moderate & 229 & 13 & 2.5 & 82 (47.6 to 140.9) \\
\hline Severe & & & & \\
\hline
\end{tabular}

*Relative risks (estimated as odds ratios in logistic regression models) are ratios of risk of recurrence and risk in reference group without index cleft cases.

†Index cases are clinically verified cleft cases without non-cleft birth defects. Recurrent cases include all recorded cases among stillborn or live born babies, cases with or without other defects, and cases that were registered either in clinical data or in medical birth registry.

¥Mean severity was estimated among clinically verified recurrent cases; 57 of 63 recurrent cleft lip cases and 20 of 25 recurrent cleft lip and palate cases were clinically verified. In cases with bilateral cleft lip, more severe of two clefts defined severity. rare syndromes that can produce both cleft lip and cleft palate only. ${ }^{14} 15$

Regarding the social impact of facial clefts, we saw a slightly decreased rate of reproduction among women with clefts and a stronger decrease for men with clefts within our follow-up period. These differences have been suggested in earlier data from Norway. ${ }^{310} \mathrm{We}$ saw no tendency for couples with one affected child to change their subsequent reproductive patterns.

\section{Genetic models of cleft inheritance}

The lack of difference between mother-offspring and father-offspring recurrence for cleft lip and cleft palate only has implications for the genetic model. ${ }^{16}$ If maternal genes operating during pregnancy had a major impact, mother-offspring recurrence should have been higher than father-offspring recurrence. The lack of such a difference also indicates that genes subject to genomic imprinting or operating through maternal mitochondrial mechanisms are not major contributors to the risk of oral clefts. Thus, fetal genes are likely to explain the great majority of genetic risk in oral clefts.

Furthermore, as we did not find sibling recurrence to be detectably higher than parent-offspring recurrence, persistent environmental factors carried by the mother apparently have much weaker effects than genes. The estimated sibling recurrence of cleft lip was higher than parent-offspring recurrence (although not significantly different), suggesting that environmental effects could be more important for cleft lip than for cleft palate only.

The absence of an effect of severity of cleft on risk of recurrence was unexpected. Previous studies of first degree relatives have reported that risk of recurrence may increase from $2.5 \%$ to $5.7 \%$, depending on the severity of the index case. However, these estimates were based on smaller numbers and coarser definitions of the severity of clefts. ${ }^{56}$ With much more statistical power and careful clinical criteria for severity, we found no evidence of an effect of severity on risk of recurrence. The mildest cleft lip produced a risk of recurrence indistinguishable from that seen with the most severe defect. Furthermore, the severity of the recurring defect in our data was unrelated to the severity of the index case.

These observations contradict standard textbooks on medical genetics, ${ }^{1718}$ which state that the familial risk of recurrence of cleft increases with severity of cleft in the proband. This increase is regarded as an example of the multifactorial threshold model of inheritance. A general principle of this model is that familial risk is greatest among relatives of the most severely affected patients. More severe disease presumably indicates a greater load in the family of the alleles assumed to predispose to disease. ${ }^{19-21}$ Another prediction of the threshold model is that if a condition is more common in one sex (say, females), then relatives of an affected male will be at a higher absolute risk than relatives of an affected female. Our data had a predominance of females in the cleft palate only category and a 


\section{WHAT IS ALREADY KNOWN ON THIS TOPIC}

The causes of oral clefts are thought to be multifactorial in nature and include several genes, environmental factors, and their interaction effects

Cleft lip and cleft palate have strong tendencies to recur in families

\section{WHAT THIS STUDY ADDS}

The anatomical severity of an isolated cleft does not seem to affect the risk of recurrence in first degree relatives

This has implications for clinical counselling, as families with mildly affected members have recurrence risks similar to families with more severely affected members, with equivalent severity among recurrent cases

predominance of males in the cleft lip category ${ }^{2}$ but we found no difference in absolute risk by sex of the index case. Our data are consistent with a few other studies suggesting that cleft lip and cleft palate do not fit the multifactorial threshold model..$^{12522-24}$ Other genetic models seem to be needed to explain why severity is nearly independent of heritability.

\section{Conclusions}

We found strong specificity of risk of recurrence for the two major types of clefts, showing their nearly distinct causes. The risk of clefts was similar among the children of affected fathers, the children of affected mothers, and the full siblings of affected cases. This pattern indicates that autosomal fetal genes make the major contribution to risk of recurrence, with little additional contribution from heritable aspects of the maternal phenotype. We found no evidence that the severity of the defect affects the risk of recurrence for either type. This raises doubts about the widely accepted multifactorial threshold model of oral cleft inheritance and opens new possibilities for a genetic model in which severity of disease is independent of genes predisposing for oral clefting.

Contributors: All authors made substantial contributions to the intellectual content of the manuscript and have all approved the final version. Ås had primary responsibility for writing the paper and analysed the data. AJW originated the study and contributed critical insights in interpretation of data. RS contributed to the design of data files and participated in interpretation of the data. HAV and FÅ provided clinical access to cases and contributed critical insights in interpretation of the data. $\mathrm{EH}$ participated in interpretation of the data. RTL originated the study, designed the study, helped in analysis of data, and contributed critical insights in interpretation of data. ÅS is the guarantor.

Funding: This work was supported by grants from the Norwegian Research Council, Helse Vest, and from NIH (2RO1 DE-11948-04). This work was supported in part by the Intramural Research Program of the NIH, National
Institute of Environmental Health Sciences and Quality Assurance Foundation II of the Norwegian Medical Association.

Competing interests: None declared.

Ethical approval: Norwegian Data Inspectorate. Studies of anonymous data from health registries do not require review by a regional committee for medical research ethics in Norway.

Provenance and peer review: Not commissioned; externally peer reviewed.

1 Mossey PA, Little J. Epidemiology of oral clefts: an international perspective. In: Wyszynski DF, ed. Cleft lip and palate: from origin to treatment . New York: Oxford University Press, 2002:127-58.

2 Sivertsen $\AA$, Wilcox A, Johnson G, Åbyholm F, Vindenes H, Lie R. Prevalence of major anatomic variations in oral clefts. Plast Reconstr Surg (in press).

3 Skjaerven R, Wilcox AJ, Lie RT. A population-based study of survival and childbearing among female subjects with birth defects and the risk of recurrence in their children. N Engl J Med 1999;340:1057-62.

4 Mitchell LE, Christensen K. Analysis of the recurrence patterns for nonsyndromic cleft lip with or without cleft palate in the families of 3,073 Danish probands. Am J Med Genet 1996;61:371-6.

5 Harper PS. Practical genetic counselling . 5th ed. Oxford: ButterworthHeinemann, 1998.

6 Firth HV, Hurst JA. Oxford desk reference clinical genetics. New York: Oxford University Press, 2005.

7 Fogh-Andersen P. Inheritance of harelip and cleft palate (thesis) University of Copenhagen, 1942.

8 Robert E, Kallen B, Harris J. The epidemiology of orofacial clefts: 1. Some general epidemiological characteristics. J Craniofac Genet Dev Biol 1996;16:234-41.

9 Lie RT, Wilcox Al, Skjaerven R. A population-based study of the risk of recurrence of birth defects. N Engl J Med 1994;331:1-4.

10 Lie RT, WilcoxAJ, Skjaerven R. Survival and reproduction among males with birth defects and risk of recurrence in their children. JAMA 2001;285:755-60.

11 Lidral AC, Murray JC. Genetic approaches to identify disease genes for birth defects with cleft lip/palate as a model. Birth Defects Res A Clin Mol Teratol 2004;70:893-901.

12 Mitchell LE, Risch N. Mode of inheritance of nonsyndromic cleft lip with or without cleft palate: a reanalysis. Am J Hum Genet 1992;51:323-32.

13 Christensen K, Mitchell LE. Familial recurrence-pattern analysis of nonsyndromic isolated cleft palate-a Danish registry study. Am J Hum Genet 1996;58:182-90.

14 Van den Boogaard MJ, Dorland M, Beemer FA, van Amstel HK. MSX mutation is associated with orofacial clefting and tooth agenesis in humans. Nat Genet 2000;24:342-3.

15 Gorlin RJ, Cohen MM, Hannekam RCM. Orofacial clefting syndromes 4th ed. New York: Oxford University Press, 2001.

16 Lie RT. Intergenerational exchange and perinatal risks: a note on interpretation of generational recurrence risks. Paediatr Perinat Epidemiol 2007;21(suppl 1):13-8.

17 Nussbaum RL, McInnes RR, Willard HF. Thompson \& Thompson genetics in medicine .6th ed. Philadelphia: W B Saunders Company, 2001.

18 Mueller R, Young I. Emery's elements of medical genetics . 11th ed. Edinburgh: Churchill Livingstone, 2001.

19 Carter CO. Genetics of common disorders. Br Med Bull 1969;25:52-7.

20 Carter CO. Multifactorial inheritance revisited. New York: Experta Medica, 1970.

21 Fraser FC. The multifactorial/threshold concept-uses and misuses. Teratology 1976;14:267-80.

22 Melnick M. Cleft lip (+/- cleft palate) etiology: a search for solutions. Am J Med Genet 1992;42:10-4.

23 Wyszynski DF, Beaty TH, Maestri NE. Genetics of nonsyndromic ora clefts revisited. Cleft Palate Craniofac J 1996;33:406-17.

24 Melnick M, Bixler D, Fogh-Andersen P, Conneally PM. Cleft lip+/-cleft palate: an overview of the literature and an analysis of Danish cases born between 1941 and 1968. Am I Med Genet 1980;6:83-97.

Accepted: 17 December 2007 